
\title{
$\angle$ Research Square \\ Multiple Endocrine Neoplasia Type 1 Involving Both Liver and Lung: A Case Report
}

\section{Jianlin Lai}

Fujian Medical University Provincial Clinical Medical College: Fujian Provincial Hospital

\section{Yangyang Huang}

Fujian Medical University Provincial Clinical Medical College: Fujian Provincial Hospital

\section{Junyi Wu}

Fujian Medical University Provincial Clinical Medical College: Fujian Provincial Hospital

Hui Cheng

Fujian Medical University Provincial Clinical Medical College: Fujian Provincial Hospital

\section{Funan Qiu ( $\nabla$ qiufunan72@163.com )}

Fujian Medical University Provincial Clinical Medical College: Fujian Provincial Hospital https://orcid.org/0000-0003-4122-728X

\section{Case report}

Keywords: case report, liver, lung, multiple endocrine neoplasia type 1, next-generation sequencing

Posted Date: October 11th, 2021

DOl: https://doi.org/10.21203/rs.3.rs-955177/v1

License: (c) (i) This work is licensed under a Creative Commons Attribution 4.0 International License. Read Full License 


\section{Abstract}

Background: Multiple endocrine neoplasia type 1 (MEN1) is a rare autosomal dominant tumor syndrome with a high degree of heterogeneity in clinical phenotypes, generally involving parathyroid, anterior pituitary and enteropancreas. In recent years, several new insights on the clinical features of MEN1 have been reported in the literature. However, it is not clear whether MEN1-associated primary tumors may occur in the liver.

Case presentation: we report the case of a 52-year-old man with multiple endocrine neoplasia type 1 diagnosed by next-generation sequencing. After Single-hole thoracoscopic right middle lobectomy, Laparoscopic radical resection of liver tumor and Radiofrequency ablation of parathyroid space, the parathyroid hormone decreased from $177 \mathrm{pg} / \mathrm{ml}$ to normal $(20 \mathrm{pg} / \mathrm{ml})$.

No local tumor recurrence was observed during a follow up of 5 months.

Conclusion: We report the first case of MEN1 with simultaneous liver and lung involvement who underwent radical resection of the tumors, and we propose the possibility that liver and other nonendocrine organs may also develop diseases associated with MEN1囚though this view needs further verification. Gene detection has crucial clinical instructive significance for diagnosis and treatment.

\section{Introduction}

MEN1 is a rare autosomal dominant tumor syndrome with a high degree of heterogeneity in clinical phenotypes. It has a high tendency for neoplasms formation in two or more organs, and often occurs in the parathyroid gland, enteropancreas and anterior pituitary[1, 2]. Since MEN1 syndrome was reported to be a genetic disease in 1997[3],more and more atypical tumors of MEN1 included - but not limited to thymic and bronchial carcinoid, breast tumorluterus tumor were found during the years[4-6]. However, primary tumor of MEN1 in the liver has not been reported. Moreover, MEN1, as a hereditary disease, no clear association between the type of gene mutation and clinical manifestations has been found[7]. These unrepresentative clinical phenotypes make diagnosis difficult, once patients were misdiagnosed, their interests will be greatly affected. Hence when the clinical manifestations are atypical, clinicians still need to be alert to consider the possibility of MEN1. We report the first case of MEN1 with simultaneous liver and lung involvement who underwent radical resection of the tumors, and we propose the possibility that primary tumors of the liver can also occur in MEN1, though this view needs further verification.

\section{Case Report}

A 52-year-old male,farmer】was admitted to our hospital due to have "liver space occupying, cholecystolithiasis" by abdominal ultrasound on July 11, 2020. There were no clinical symptoms such as abdominal pain, abdominal distension, acid regurgitation, jaundice, rash and so on. The enlarged thyroid gland and parathyroid gland were not palpated by physical examination, and no obvious abnormality was found in abdominal specialist examination. More than 20 years ago, "pituitary adenoma resection" 
was performed in a tertiary referral hospital in Fujian Province because of "pituitary adenoma". The history of "kidney stone" was found for 5 years. He has neither a history of smoking nor drinking. In addition, two years ago, his mother underwent laparoscopic distal pancreatectomy for "pancreatic tumor" in our hospital, postoperative pathology revealed pancreatic neuroendocrine tumor (G2). The imaging findings of our hospital suggested metastatic tumor in IV and VI segments of the liver, multiple hemangiomas in VIII segment of the liver, central-type lung cancer of middle lobe of right lung, parathyroid adenoma, bilateral adrenal multiple adenomas $\llbracket$ cholecystolithiasis with chronic cholecystitis, right kidney stone (Fig. 1A-C, G). According to the above auxiliary examination, lung cancer with liver metastasis was considered in the initial diagnosis. Then this patient transferred to a tertiary referral hospital in Fujian Province, where ultrasound-guided fine-needle aspiration (US-FNA) cytology was performed on parathyroid gland, lung and liver lesions, suggesting lung adenocarcinoma with liver metastasis, but it is interesting that no tumor cells were found in parathyroid mass. After 2 cycles of neoadjuvant chemotherapy (Paclitaxel + Lobaplatin), Single-hole thoracoscopic right middle lobectomy plus mediastinal lymph node dissection were performed on October 14, 2020. The operation was smooth and there were no obvious complications after operation. Postoperative pathology showed atypical adenocarcinoma in the middle lobe of the right lung, tumor thrombus in the vein, no invasion of pulmonary membrane and lymph nodes. Immunohistochemical results were summarized as follows: CK(+); TTF-1(-); NapsinA(-); P63(-); P40(-); P53(-); CD56(+); CgA(+); Syn(+); Ki-67 5\%(+); SSTR2(+); ATRX $(+) ; \operatorname{DAXX}(+)$. Then the patient was diagnosed as atypical adenocarcinoma liver metastasis in the middle lobe of the right lung(PT2NOM1). Regrettably, MEN1 was not diagnosed when discharged from hospital.

The patient was then revisited to our center on December 14,2020. There was no abnormality in the special physical examination, routine blood, serum biochemistry, coagulation index. However, the liver MRI showed that the liver tumor was more advanced than before (Fig. 1D-F) and parathyroid adenoma was suggested by Thyroid SPECT/CT (Figure 1H,I). Various hormone indexes were examined before

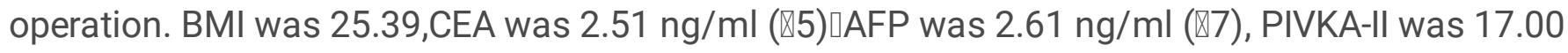

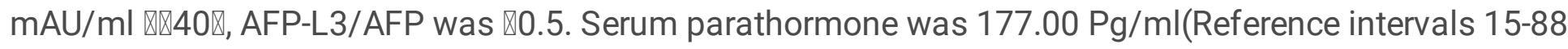
$\mathrm{Pg} / \mathrm{ml}$, Same as below), serum calcium was $2.82 \mathrm{mmol} / \mathrm{L}$ (2.11-2.52), serum phosphorus was 0.88 $\mathrm{mmol} / \mathrm{L}$ (0.85-1.51), adrenocorticotrophic hormone was $12.7 \mathrm{pg} / \mathrm{ml}$ (7.2-63.6), renin (upright posture) was

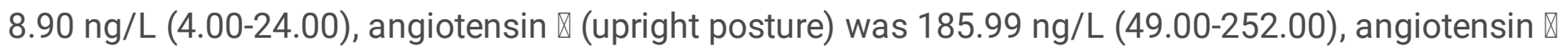
(lying posture) was $160.43 \mathrm{ng} / \mathrm{L}$ (25.00-129.00), aldosterone (upright posture) was $14.23 \mathrm{ng} / \mathrm{dL}$ (4.0031.00 ), aldosterone (lying posture) was $8.10 \mathrm{ng} / \mathrm{L}$ (1.00-16.00), cortisol (8Am) was $262.32 \mathrm{ng} / \mathrm{L}$ (240 680 ), cortisol (4Pm) was $170.97 \mathrm{nmol} / \mathrm{L}$ ( $(276.00)$, sex hormone binding globulin was $55.91 \mathrm{nmol} / \mathrm{L}$ (14.5-48.4), dehydroepiandrosterone was $58.50 \mathrm{ug} / \mathrm{dL}$ (38-313), follicle-stimulating Hormone was 3.51 $\mathrm{IU} / \mathrm{L}$ (1.27-19.26), luteinizing hormone was $1.46 \mathrm{IU} / \mathrm{L}(1.25-8.63)$, prolactin was $6.54 \mathrm{ng} / \mathrm{ml}$ (2.64-13.13), growth hormone was $0.02 \mathrm{ng} / \mathrm{ml}(0.004-1.406)$, testosterone was $1.80 \mathrm{nmol} / \mathrm{L}$ (6.07-27.24), progesterone was $0.86 \mathrm{ng} / \mathrm{ml}$ (0.1-0.84), estradiol was $14.54 \mathrm{Pg} / \mathrm{ml}$ (15-38.95), plasma insulin was $9.93 \mathrm{mU} / \mathrm{L}$ (2.624.9), c-Peptide was $3.03 \mathrm{Ug} / \mathrm{L}$ (1.1-4.4), dopamine was $93.8 \mathrm{pmol} / \mathrm{L}$ ( $\leq 195.7)$, adrenaline was 86.9

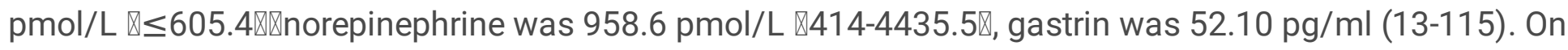


the basis of present evidence, a clinical diagnosis of MEN1 could be made. Blood sample was taken for next-generation sequencing (Fig. 2), which indicated that MEN1 gene had a deletion mutation of GTCT in chr11:64577329, resulting the mutation of amino acid No. 85 from isoleucine to serine, then an early termination signal was generated at the 33rd position of the new reading frame, then the normal protein function loss. At the same time, we conducted genetic tests on 7 first-degree relatives of the propositus and found that there was a germline mutation of men1c.249-252del (p. ile855erfster33), which was the same as the propositus (Fig. 3).

After multidisciplinary consultation (the department of endocrinology, basic surgery, urology and anesthesiology), Radio-frequency Ablation(RFA) of right liver tumor(one in S6, two in S7 and one in S8), laparoscopic resection of liver tumor in VI, endoscopic RFA of liver tumor (one in S4, one in S5 and one in S6) and cholecystectomy were performed on December 24, 2020 (Fig. 4A-D,F). The operation was smooth and the postoperative recovery was good. RFA of left and right lower pole parathyroid mass was performed on December 28, 2020 and December 29, 2020 respectively. Then we performed a hematologic review of the patient, parathyroid hormone was decreased to $20.57 \mathrm{pg} / \mathrm{ml}$, serum calcium was 2.09 $\mathrm{mmol} / \mathrm{L}$, and serum phosphorus was $1.02 \mathrm{mmol} / \mathrm{L}$, as expected (Fig. 5). Though the cell morphology were atypical under light microscope, the combination of immunohistochemical results, $\mathrm{CgA}(+++)$; CD56(+++); Syn(+++); TTF(-); Ki67(15\%+);NapsinA(-); CK(pan)(+++); CK18(+++); Heparl(-); CK19(+++); Glypican3 (-), suggested atypical carcinoid of the liver (figure 4E). Then the final diagnoses were as below: 1. Multiple endocrine adenomatosis (MEN1), 2. Multiple atypical carcinoid in the liver, 3. Cholecystolithiasis with chronic cholecystitis, 4. Primary hyperparathyroidism, 5. Multiple parathyroid adenomas, 6 . Right kidney calculi, 7. Multiple adrenal adenomas. No local tumor recurrence was observed in liver during a follow-up of 5 months,and there was no significant change in the size of adrenal nodules(Fig. 4G-I).

\section{Discussion And Conclusions}

In 1977, MEN1 gene was first reported[3], which located in chromosome 11q13 and expressed in cells throughout the body, acting as an autosomal dominant tumor suppressor gene. At present, the theory of second strike of genes is widely accepted as the pathogenicity hypothesis of this disease[8]. Homozygous mice with MEN1 gene deletion will die in the uterus. After the birth of heterozygotes, when the second somatic frameshift mutation, nonsense mutation, missense mutation, frame deletion or insertion, site splicing and other mutations in the MEN1 allele occur after the birth of the heterozygote, the organs are likely to develop the disease. The diagnosis of MEN1 includes three aspects[2]: 1) two or more MEN1-related primary endocrine tumors (pituitary, parathyroid or pancreas) in the same individual. 2) gene detection of MEN1 gene mutation. 3) first-degree relatives of MEN1 patients with at least one MEN1related tumor. MEN1 can be diagnosed by satisfying one of them. In this case, this patient underwent transsphenoidal adenomectomy for pituitary tumor 20 years ago, and now he was treated because of "finding liver space". Multiple space-occupying lesions of the whole body were found by imaging. Pathological biopsy showed that the liver and lung lesions were endocrine tumors. Blood samples showed men1c.249-252del (p.ile855erfsTer33) germline mutation, which could be diagnosed as MEN1 
both clinically and genetically. The incidence of non-endocrine organs is so low that clinicians do not pay enough attention to this clue. It was not until the patient revisited to our hospital that MEN1 was considered after multidisciplinary consultation. Then the whole genome sequencing for the patient was brought into schedule, and 7 of his first-degree relatives were screened for MEN1 gene.

As a hereditary disease, the importance of gene detection for diagnosis and treatment is self-evident. The guidelines recommend genetic testing for the following situations[1,2]: 1) there are two or more typical or atypical tumors related to MEN1. 2)parathyroid adenomas occurring before the age of 30 or multiple parathyroid diseases, multiple pancreatic neuroendocrine tumors or gastrinomas at any age. 3) first degree relatives of patients diagnosed clinically, genetically and pedigree. It has been confirmed that the survival time of patients with MEN1 gene mutation is shorter than that of patients without gene mutation. Once the gene test is positive, close clinical follow up observation should be carried out according to the guidelines in order to achieve early detection, early diagnosis, early treatment and improve survival time. First degree relatives of patients are also recommended for MEN1 gene screening to identify which family members need to enter the clinical observation process, early detection and treatment of complications caused by endocrine hormones, and more importantly, early detection of highly malignant lesions will increase tumor R0 resection rate, so that patients have a longer survival time[7, 9, 10]. One patient with the same MEN1 gene mutation as the proband was found in this pedigree, and there was no clinical phenotype at present. Regular imaging and hematological follow up of the proband and his MEN1 gene mutation positive relatives will be beneficial to improve the quality of life and survival time of the patients.

At present, MEN1-related endocrine adenomas are treated with reference to sporadic endocrine adenomas, and radical resection is the first choice for treatment. However, the guidelines do not clearly point out the differentiation and treatment strategies of primary and metastatic lesions found in multiple tumors at the same time. Even for highly malignant intestinal tumors, the 5-year survival rate can reach $80 \%$ in the case of radical resection of intestinal primary and metastatic lesions. And the perioperative mortality was less than $5 \%$. Even in order to improve endocrine syndrome-related symptoms and improve the quality of life of patients, it is feasible to operate a cytoreductive surgery to improve the overall survival and reduce the endocrine level of $95 \%$ of patients[11-13].

In our case, we carried out genetic testing on patients in time (though not at the first time) and confirmed the existence of MEN1 gene mutation. Minimally invasive liver tumor resection combined with intraoperative liver radiofrequency ablation(RFA) was used to reserve healthy liver tissue as much as possible. Percutaneous radiofrequency ablation of parathyroid tumors, which not only ensured the radical effect, but also prevented patients from undergoing too many major spinal surgery in a short time, thus avoiding the negative psychological generation of patient.

No scholar has suggested that MEN1-related primary tumors might occur in liver. Though liver metastasis may occur in MEN1-related duodenopancreatic tumors[14] and thymic tumors[15], while liver metachronous metastasis is reported in MEN1-related lung tumors[16]. No liver metastasis was reported 
in pituitary tumor and parathyroid tumor. In our case, the discovery of liver and pulmonary tumors was synchronous, and the lesions were in a state of radically resectable. And as mentioned above, The level of parathyroid hormone returned to normal after Single-hole thoracoscopic right middle lobectomy, liver lesions resection and radiofrequency ablation of parathyroid glands. What is more, No local tumor recurrence was observed during a follow up of 5 months. As far as we know, there have been no similar reports.

The biggest deficiency is that it is not completely clear whether the nature of lung and liver tumors were multifocal primary tumors or metastasis. However, Most MEN1-related tumors are benign, the characteristics of MEN1 that tumors can appear in the form of multiple organs and multiple lesions all over the body, moreover》 liver and lung biopsy of the patient showed the tumors belonged to highly differentiated type, the probability of distant metastasis was relatively low[17], and no new lesions were found after 5 months follow-up, we put forward the hypothesis that liver and lung may have multifocal primary tumors at the same time. Further[we propose the possibility that primary tumors of the liver can also occur in MEN1, though this view needs further verification.

In this patient, SPECT/CT found that there was a hypermetabolic mass in each of the bilateral inferior thyroid poles, and the possibility of bilateral inferior parathyroid adenoma was considered because of the increasing parathyroid hormone to 177PG / $\mathrm{ml}$ and the increasing serum calcium. So the primary hyperparathyroidism (PHPT) could be diagnosed. At present, the best time and scope of parathyroid surgery is still controversial. According to the guidelines, more than 3.5 thyroid glands should be removed in this patient[2], but the possibility of permanent parathyroid dysfunction after extensive parathyroid surgery is as high as $40 \%$. Severe hypercalcemia or parathyroid carcinoma is rare in patients with MEN1related PHPT, and the main goal of treatment is the control of parathyroid hormone. When the number of enlarged parathyroid glands is less than 2, the scope of parathyroidectomy can be reduced as much as possible and individualized treatment can be realized[18, 19]. It has been confirmed that ultrasoundguided radiofrequency ablation of parathyroid adenoma is effective and safe[18, 20]. The normal range of parathyroid hormone $(20 \mathrm{pg} / \mathrm{ml})$ caused by the decrease of parathyroid hormone $(177 \mathrm{pg} / \mathrm{ml})$ after operation suggested that the treatment was effective and there were no obvious complications after operation. The deficiency was that parathyroid hormone was not reexamined in the follow up of patients.

Abdominal MRI also found multiple adrenal adenomas, however, Hematological analysis results did not suggest aldosteronism or hypercortisolaemia. In addition, no increased adrenal metabolism was found in PET-CT, continued follow up observation were therefore required. Surgical resection is considered when symptoms occur, tumors grow obviously or is larger than $4 \mathrm{~cm}[2]$.

The patient recovered well after surgical treatments, he said that he would strictly follow the doctor's advice $\llbracket$ adding, "I would also urge relatives who carry pathogenic genes to conduct clinical follow up". Both doctors and the patient are full of confidence in obtaining high-quality and long-term survival in the future. 
In summary, the clinical phenotype of MEN1 comes in variety forms, and atypical related organs such as liver and lung endocrine tumors are easy to miss diagnosis of this disease. When suspected of this disease, we should carry out comprehensive laboratory indicators, imaging examination, gene detection and other screening. Also, multidisciplinary consultation is recommended when MEN1 is suspected for the sake of reducing the rate of missed diagnosis. Final goal is to increase survival time and improve quality of life by early discovery, early diagnosis and early treatment.

\section{Abbreviations}

\section{MEN1}

Multiple endocrine neoplasia type 1

US-FNA

Ultrasound-guided fine-needle aspiration

MRI

Magnetic resonance imaging

SPECT/CT

Single-photon emission computed tomography-computed tomography

CEA

Carcinoembryonic antigen

AFP

a-fetoprotein

PIVKA-II

Protein Induced by Vitamin K Absence or Antagonist-II

RFA

Radio-frequency Ablation

PHPT

Primary hyperparathyroidism

PET-CT

Positron Emission Tomography - Computed Tomography

\section{Declarations}

\section{Ethics approval and consent to participate}

Ethical approval was obtained from the Ethics Committee of Fujian Provincial Hospital of Fujian Medical University, Fuzhou, China. Written informed consent to participate in this study was obtained from the patient.

\section{Consent for publication}




\section{Availability of data and materials}

All data generated or analyzed during this study are included in this published article.

\section{Competing interests}

The authors declare that they have no competing interests.

\section{Funding}

None

\section{Authors' contributions}

Funan Qiu and Jianlin Lai managed the case. Yangyang Huang and Junyi Wu collected patient data and image. Hui Cheng did histopathological analysis. Jianlin Lai and Yangyang Huang wrote the manuscript. Funan Qiu conducted the research and revised the manuscript.

\section{Acknowledgments}

We thank the patient and his relatives to take part in this study.

\section{References}

1. Kamilaris CDC, Stratakis CA. Multiple Endocrine Neoplasia Type 1 (MEN1): An Update and the Significance of Early Genetic and Clinical Diagnosis. Front Endocrinol (Lausanne). 2019;10:339.

2. Thakker RV, Newey PJ, Walls GV, Bilezikian J, Dralle H, Ebeling PR, Melmed S, Sakurai A, Tonelli F, Brandi ML, Endocrine S. Clinical practice guidelines for multiple endocrine neoplasia type 1 (MEN1). J Clin Endocrinol Metab. 2012;97:2990-3011.

3. Chandrasekharappa S, Guru S, Manickam P, Olufemi S, Collins F, Emmert-Buck M, Debelenko L, Zhuang Z, Lubensky I, Liotta L, et al: Positional cloning of the gene for multiple endocrine neoplasiatype 1. 1997, 276:404-407.

4. Dreijerink K, Goudet P, Burgess J, Valk G, JTNEjom. Breast-cancer predisposition in multiple endocrine neoplasia type 1. 2014, 371:583-584.

5. Falchetti A, Marini F, Luzi E, Giusti F, Cavalli L, Cavalli T. Brandi MJGimojotACoMG: Multiple endocrine neoplasia type 1 (MEN1): not only inherited endocrine tumors. 2009, 11:825-835. 
6. McKeeby J, Li X, Zhuang Z, Vortmeyer A, Huang S, Pirner M, Skarulis M, James-Newton L, Marx S. Lubensky IJTAjop: Multiple leiomyomas of the esophagus, lung, and uterus in multiple endocrine neoplasia type 1. 2001, 159:1121-1127.

7. Mele C, Mencarelli M, Caputo M, Mai S, Pagano L, Aimaretti G, Scacchi M, Falchetti A. Marzullo PJFie: Phenotypes Associated With MEN1 Syndrome: A Focus on Genotype-Phenotype Correlations. 2020, 11:591501.

8. Knudson, AJPotNAoSotUSoA. Mutation and cancer: statistical study of retinoblastoma. 1971, 68:820-823.

9. de Laat J, van Leeuwaarde R. Valk GJFie: The Importance of an Early and Accurate MEN1 Diagnosis. 2018, 9:533.

10. Pieterman C, Hyde S, Wu S, Landry J, Chiang Y, Christakis I, Grubbs E, Fisher S, Graham P, Waguespack S, Perrier NJS. Understanding the clinical course of genotype-negative MEN1 patients can inform management strategies. 2021, 169:175-184.

11. Pavel M, Baudin E, Couvelard A, Krenning E, Öberg K, Steinmüller T, Anlauf M, Wiedenmann B, Salazar R, JN: ENETS Consensus Guidelines for the management of patients with liver and other distant metastases from neuroendocrine neoplasms of foregut, midgut, hindgut, and unknown primary. 2012, 95:157-176.

12. Pavel M, Öberg K, Falconi M, Krenning E, Sundin A, Perren A, Berruti A, JAooojotESfMO. Gastroenteropancreatic neuroendocrine neoplasms: ESMO Clinical Practice Guidelines for diagnosis, treatment and follow-up. 2020, 31:844-860.

13. van Beek D, Nell S, Vorselaars W, Bonsing B, van Eijck C, van Goor H, Nieveen van Dijkum E, Dejong C, Valk G. Borel Rinkes I, Vriens MJAoso: Complications After Major Surgery for Duodenopancreatic Neuroendocrine Tumors in Patients with MEN1: Results from a Nationwide Cohort. 2021.

14. Vinault S, Mariet A, Le Bras M, Mirallié E, Cardot-Bauters C, Pattou F, Ruszniewski P, Sauvanet A, Chanson P, Baudin E, et al: Metastatic Potential and Survival of Duodenal and Pancreatic Tumors in Multiple Endocrine Neoplasia Type 1: A GTE and AFCE Cohort Study (Groupe d'étude des Tumeurs Endocrines and Association Francophone de Chirurgie Endocrinienne). 2020, 272:1094-1101.

15. Goudet P, Murat A, Cardot-Bauters C, Emy P, Baudin E, du Boullay Choplin H, Chapuis Y, Kraimps J, Sadoul J, Tabarin A, et al: Thymic neuroendocrine tumors in multiple endocrine neoplasia type 1: a comparative study on 21 cases among a series of 761 MEN1 from the GTE (Groupe des Tumeurs Endocrines). 2009, 33:1197-1207.

16. van den Broek M, de Laat J, van Leeuwaarde R, van de Ven A, de Herder W, Dekkers O, Drent M, Kerstens M, Bisschop P, Havekes B, et al: The Management of Neuroendocrine Tumors of the Lung in MEN1: Results From the Dutch MEN1 Study Group. 2021, 106:e1014-e1027.

17. Shah M, Goldner W, Halfdanarson T, Bergsland E, Berlin J, Halperin D, Chan J, Kulke M, Benson A, Blaszkowsky L, et al: NCCN Guidelines Insights: Neuroendocrine and Adrenal Tumors, Version 2.2018. 2018, 16:693-702. 
18. Versnick M, Popadich A, Sidhu S, Sywak M, Robinson B, Delbridge LJS: Minimally invasive parathyroidectomy provides a conservative surgical option for multiple endocrine neoplasia type 1primary hyperparathyroidism. 2013, 154:101-105.

19. Horiuchi K, Sakurai M, Haniu K, Nagai E, Tokumitsu H, Yoshida Y, Omi Y, Sakamoto A. Okamoto TJWjos: Impact of "Tailored" Parathyroidectomy for Treatment of Primary Hyperparathyroidism in Patients with Multiple Endocrine Neoplasia Type 1. 2018, 42:1772-1778.

20. Liu F, Yu X, Liu Z, Qiao Z, Dou J, Cheng Z, Han Z, Yu J. Liang PJljohtojoESfHO, North American Hyperthermia Group: Comparison of ultrasound-guided percutaneous microwave ablation and parathyroidectomy for primary hyperparathyroidism. 2019, 36:835-840.

\section{Figures}
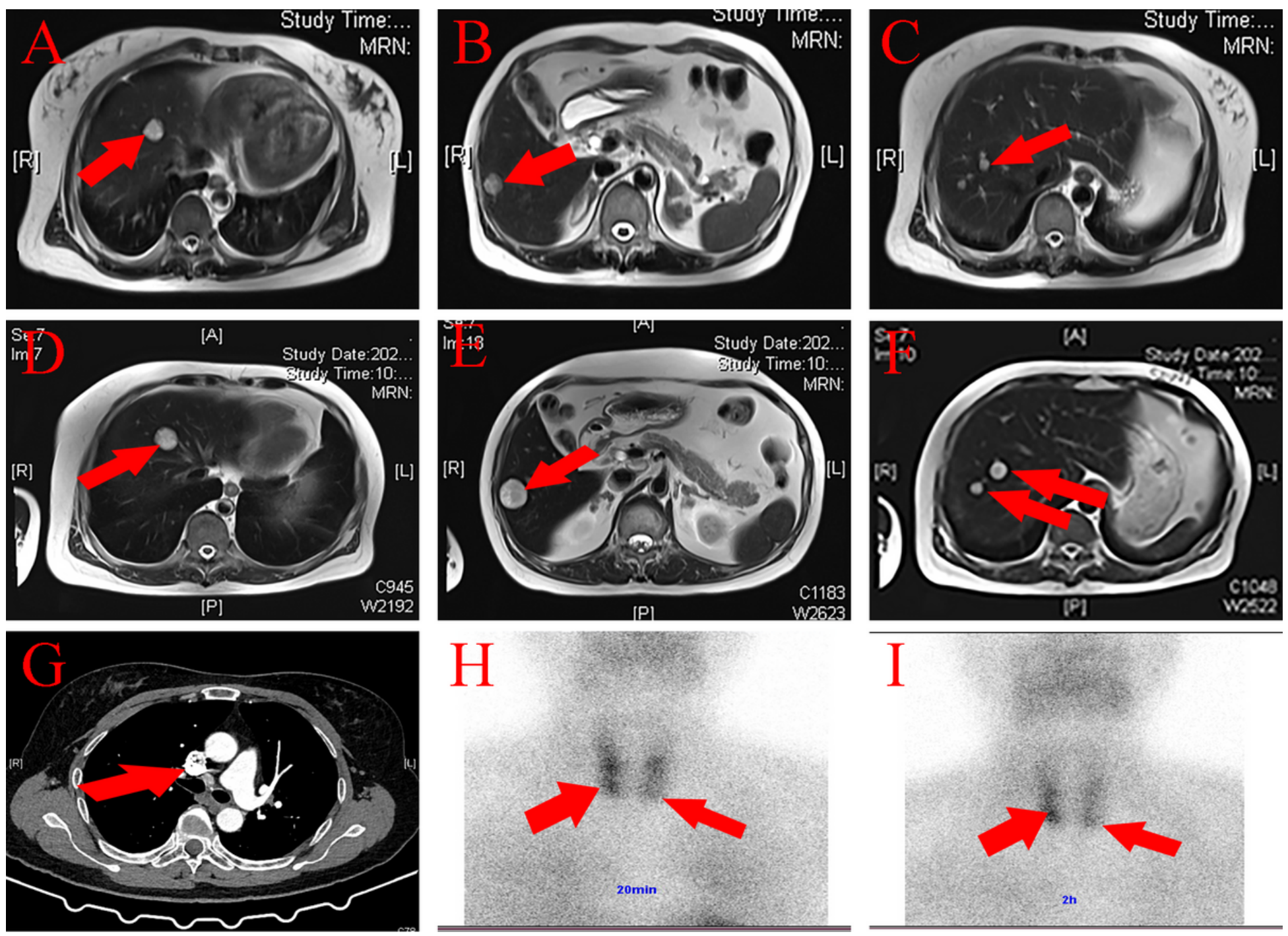

Figure 1

Clinical features before hepatectomy. The red arrows point to the location of lesions. (a),(b),(c) Multiple lesions were found in $\forall \nabla \nabla$ and $\nabla$ segments with the largest diameter of about $1.8 \mathrm{~cm}$ by $T 2$ - weighted 
magnetic resonance image of liver in July 2020 . (d),(e),(f) Multiple lesions in $\nabla \nabla \nabla$ and $\nabla$ segments were larger than before, with a largest diameter of about $2.9 \mathrm{~cm}$ in December, 2020. (g) In July, 2020, Computed tomography (CT) enhanced arterial phase showed the tumor, about $3.7 \mathrm{~cm} \times 2.7 \mathrm{~cm}$ in size, located in the middle lobe of right lung and exhibited a inhomogeneous enhancement. (h),(i) In December, 2020, Technetium-99m SESTAMIBI at 20 min and 2 hour suggested parathyroid adenomas located in the lower poles of both sides.

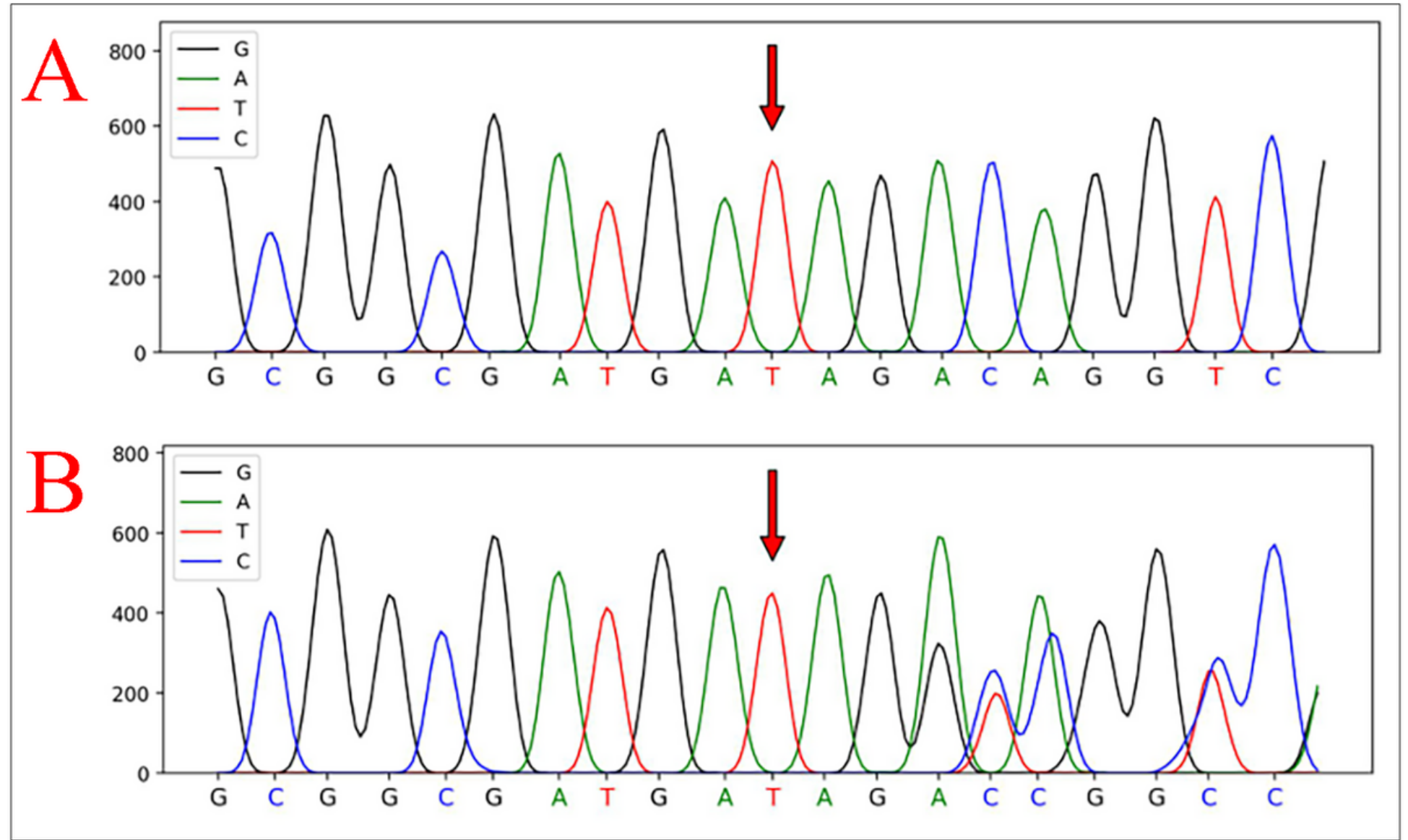

Figure 2

The result of next-generation sequencing. (a) The reference genetic sequence of MEN1. (b) The genetic sequence of proposita showing mutations in chr11:64577329.(c) Pedigree chart of proposita and his first-degree relatives. 


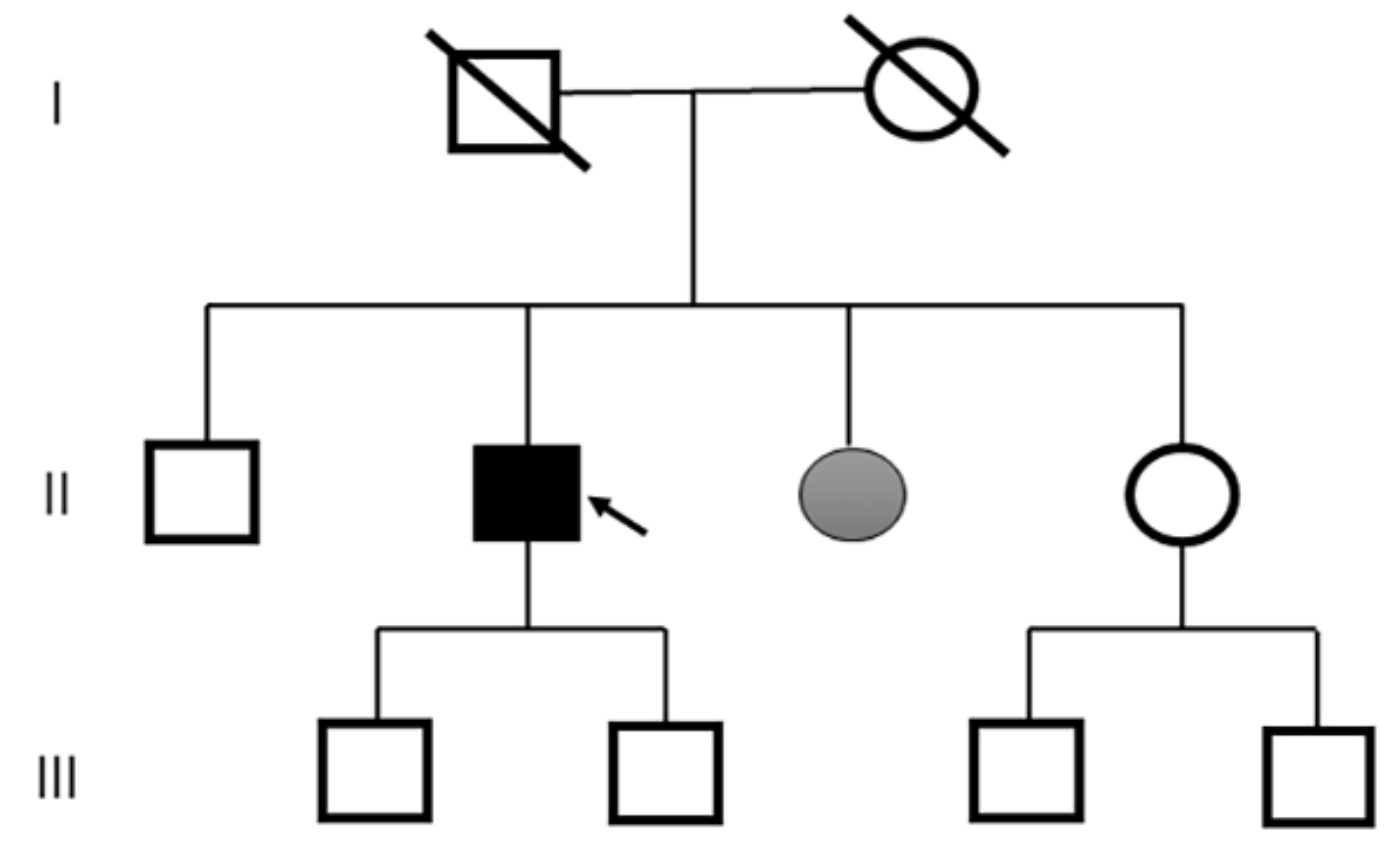

\section{KEY}

\section{$\boldsymbol{\nabla}$ Deceased male $\boldsymbol{\square}$ Normal male $\boldsymbol{\square}$ Proposita Q Decease female $\bigcirc$ Normal female $\bigcirc$ Affected female}

Figure 3

The family tree of the patient.

政

Figure 4

Clinical features of intraoperative and postoperative follow-up. The red arrows point to the location of lesions. (a) laparoscopic ultrasound $\mathbb{\text { LUS }} \otimes$ showing high echo signal of the tumor in S4 segment of liver

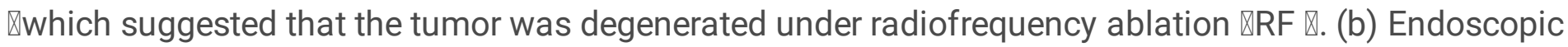
image of radiofrequency ablation in S4 segment of the liver. (c) Laparoscopic resection of liver mass in S4 segment. (d) Gross specimen of the tumor in S4 segment with a section size of about $3 \times 3 \mathrm{~cm}$, which had fish-flesh appearance. (e) Microscopic (histologic) image(HEx40) suggested atypical carcinoid of S4 segment of the liver. (f) The gross specimen of cholecyst which was filled with gallstones. (g),(h) Arterial phase of magnetic resonance imaging of the liver. No tumor recurrence was found in the operative area. The liver lesions in the area of radiofrequency ablation showed coagulative necrosis. (i) Arterial phase of magnetic resonance imaging. Adrenal space occupying lesion, $2.8 \mathrm{~cm} \star 2.4 \mathrm{~cm}$, with heterogeneous 
enhancement, was considered as adrenal adenoma. And there was no significant change in diameter of the tumor.

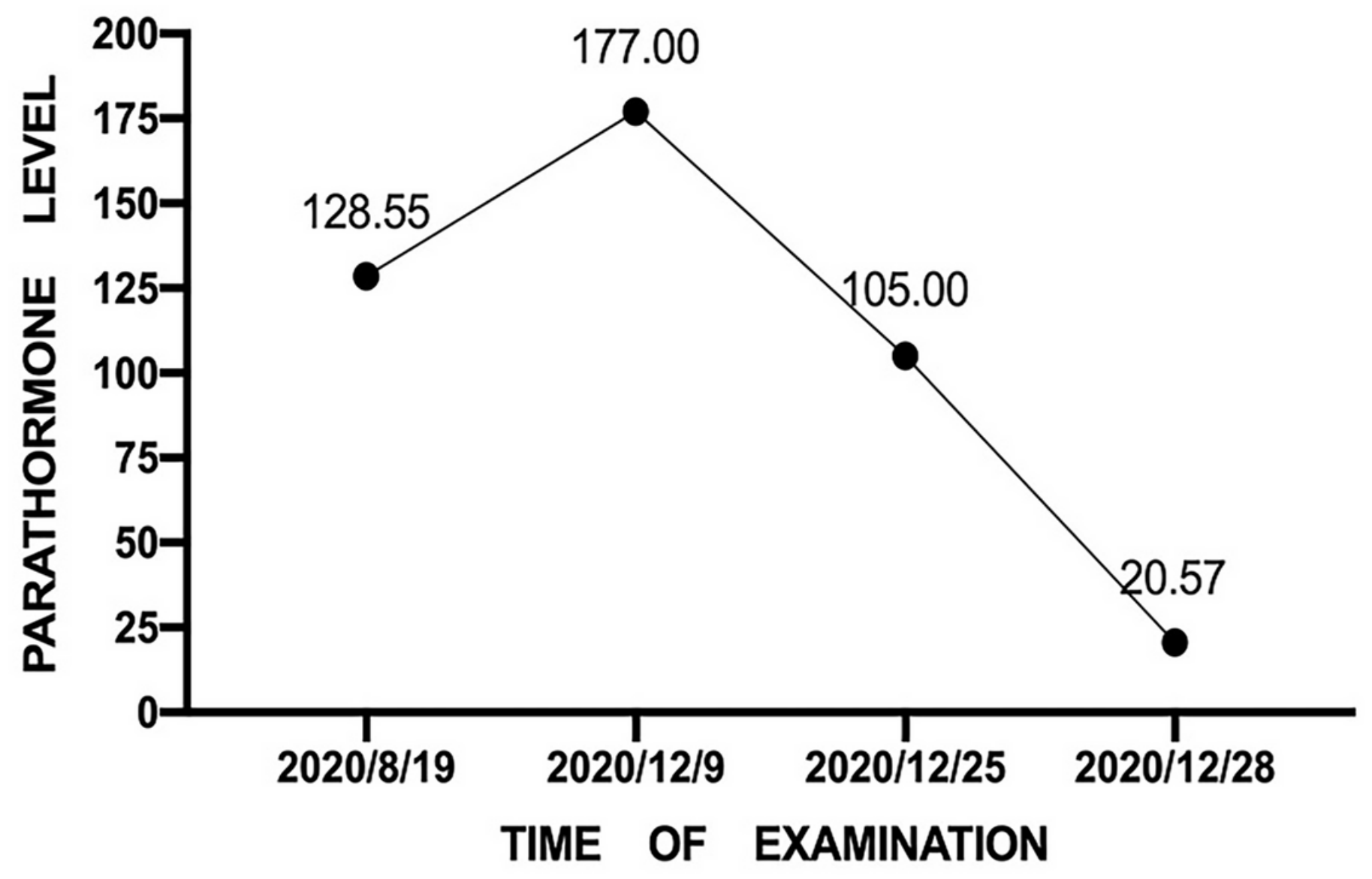

Figure 5

Change trend of parathyroid hormone in the course of disease. 